\title{
Synthesis, characterization and evaluation of the chemosensory ability of benzothiazolium salts bearing a triphenylamino donor group and an aryl spacer
}

\author{
R. Cristina M. Ferreira, Susana P. G. Costa and M. Manuela M. Raposo* \\ Centro de Química, Universidade do Minho, Campus de Gualtar, 4710-057 Braga, \\ mfox@quimica.uminho.pt
}

\begin{abstract}
The new benzothiazolium salts derivatives 3a-b were obtained in moderate yields through a Knoevenagel reaction. The new compounds were characterized by the usual spectroscopic techniques and a detailed photophysical study was undertaken. The evaluation of the compounds as colorimetric chemosensors was carried out by performing spectrophotometric titrations in acetonitrile and acetonitrile/water in the presence of relevant organic and inorganic anions, and of alkaline, alkaline-earth and transition metal cations.
\end{abstract}

Keywords: Colorimetric sensors; Triphenylamine derivatives, Knoevenagel reaction; Benzothiazolium salts. 


\section{Introduction}

Organic salts are the focus of much recent attention, in part due to their stability and the ease of tailoring for specific physical properties. In particular, styryl-pyridinium and benzothiazolium salts have been widely applied in diverse areas such as NLO-phores, frequency-upconversion, optical power limiting, fluorescent probes, laser scanning fluorescence microscopy, molecular switches, etc. ${ }^{1}$

The recognition and detection of ionic species has aroused great interest due to their important roles in many biological and environmental processes. Several sensor systems have been developed but most present some limitations in terms of sensitivity, selectivity, and simplicity. Colorimetric chemosensors are molecules that allow nakedeye detection of ionic species without resource to any instrumentation, offering qualitative and quantitative information. These chemical sensors are considered as one of the most effective analytical methods for environmental monitoring, particularly in the detection of metal ions whose presence in the environment has serious consequences. Additionally, chemosensors soluble in aqueous media are very appealing, because of the importance in sensing species in biological processes, disease states and environmental pollution. ${ }^{2}$

In this work, we report the synthesis of two benzothiazolium salts $\mathbf{3 a - b}$, substituted at position 2 with a triphenylamino donor group and an aryl spacer with different electronic character, in order to evaluate their photophysical properties and chemosensory ability.

\section{Experimental}

\subsection{Synthesis of 2,3-dimethylbenzo[d]thiazol-3-ium iodide 1}

A solution of 2-methylbenzothiazole $(3.36 \mathrm{mmol})$ in acetonitrile $(5 \mathrm{~mL})$ was added to methyl iodide $(20 \mathrm{mmol})$. The solution was stirred at reflux for $6 \mathrm{~h}$. The precipitate was filtred and washed with acetonitrile to give the pure salt. 


\subsection{General procedure for the synthesis of benzothiazolium salts $3 a-b$}

A solution of aldehyde $\mathbf{2 a}$ or $\mathbf{2 b}(0.37 \mathrm{mmol})$, benzothiazolium salt $\mathbf{1}(0.37 \mathrm{mmol})$ and piperidine (1 drop) in ethanol $(5 \mathrm{~mL})$ was heated at reflux for $6 \mathrm{~h}$. After this time the solvent was evaporated and the resulting crude product was recrystallized from dichloromethane / diethyl ether.

2.2.1. Compound 3a was obtained as a dark red solid (92 mg, 46\%). Mp. 162.7-163.5 ${ }^{\circ} \mathrm{C}$. UV-vis (acetonitrile): $\lambda_{\max } \mathrm{nm}(\log \varepsilon) 509$ (4.31). ${ }^{1} \mathrm{H}$ NMR (DMSO- $\left.d_{6}\right): \delta=4.25$ (s, $\left.3 \mathrm{H}, \mathrm{CH}_{3}\right), 6.88$ (d, J = 8.8 Hz, 2H, H-2' and H-6'), 7.17-7.24 (m, 6H, 2x (H-2, H-4 and H-6)), 7.70-7.44 (m, 4H, 2x (H-3 and H-5)), 7.71 (dd, J = 0.8 and $8.0 \mathrm{~Hz}, 1 \mathrm{H}, \mathrm{H}-5$ ') $)$, 7.76 (d, J = $16 \mathrm{~Hz}, 1 \mathrm{H}, \mathrm{H}-\mathrm{b}), 7.81$ (dt, J = 1.2 and $8.4 \mathrm{~Hz}, 1 \mathrm{H}, \mathrm{H}-6$ ') $), 7.90$ (d, J = 8.8 Hz, 2H, H-3' and H-5'), 8.09 (d, J = 16 Hz, 1H, H-a), 8.17 (d, J = 8.4 Hz, 1H, H-7' '), $8.36\left(\mathrm{dd}, \mathrm{J}=0.8\right.$ and $8.0 \mathrm{~Hz}, 1 \mathrm{H}, \mathrm{H}-4$ '”) ppm. ${ }^{13} \mathrm{C}$ NMR (DMSO- $\left.d_{6}\right): \delta=36.16\left(\mathrm{CH}_{3}\right)$, 110.07 (C-b), 116.47 (C-7'’), 118.92 (C-2' and C-6'), 124.03 (C-4'’), 125.46 (C-4), 126.16 (C-2 and C-6), 127.34 (C-3'”), 127.99 (C-5'), 129.18 (C-6), 130.02 (C-3 and C5), 131.86 (C-3' and C-5'), 141.96 (C-8'’), 145.46 (C-1), 148.54 (C-a), 151.33 (C-1'), $171.64(\mathrm{C}-2$ '”) ppm.

2.2.2. Compound 3b was obtained as a dark red solid (15 mg, 12\%). M.p. 223.8-224.7 ${ }^{\circ} \mathrm{C}$. UV-vis (acetonitrile): $\lambda_{\max } \mathrm{nm}(\log \varepsilon) 558$ (4.11). ${ }^{1} \mathrm{H}$ NMR (DMSO- $\left.d_{6}\right): \delta=4.36(\mathrm{~s}$, $\left.3 \mathrm{H}, \mathrm{CH}_{3}\right), 7.04$ (d, J = 8.8 Hz, 2H, H-2' and H-6'), 7.07-7.12 (m, 6H, 2x (H-2, H-4 and H-6)), 7.33 - 7.37 (m, 4H, 2x (H-3 and H-5)), 7.75 (d, J = 8.8 Hz, 2H, H-3' and H-5'), 7.79 (dt, $\mathrm{J}=1.2$ and 7.2 Hz, 1H, H-5"' '), 7.85-7.90 (m, 3H, H-3', H-5', and H-6','), 8.06 (d, J = $15.6 \mathrm{~Hz}, 1 \mathrm{H}, \mathrm{H}-\mathrm{b}), 8.12$ (d, J = 8.4 Hz, 2H, H-2', and H-6' '), 8.24 (d, J = $15.6 \mathrm{~Hz}, 1 \mathrm{H}, \mathrm{H}-\mathrm{a}), 8.25$ (d, J = 8.4 Hz, 1H, H-7', '), 8.42 (dd, J = 0.8 and $8.0 \mathrm{~Hz}, 1 \mathrm{H}, \mathrm{H}-$ $\left.4{ }^{\prime, \prime}\right)$ ppm. ${ }^{13} \mathrm{C}$ NMR (DMSO-d $\left.d_{6}\right): \delta=36.40\left(\mathrm{CH}_{3}\right), 113.42$ (C-b), 116.88 (C-7','), 122.51 (C-2' and C-6'), 123.73 (C-4), 124.25 (C-4','), 124.60 (C-2 and C-6), 126.54 (C-3' ' and C-5'), 127.87 (C-3','), 127.93 (C-3' and C-5'), 128.44 (C-5','), 129.43 (C6','), 129.72 (C-3 and C-5), 130.55 (C-2'” and C-6'), 131.93 (C-4'), 132.54 (C-1'), 142.08 (C-8','), 143.13 (C-4’'), 146.75 (C-1), 147.77 (C-1'), 148.12 (C-a), 171.89 (C2',') ppm. 


\subsection{Spectrophotometric titrations of compounds $3 \mathbf{a}-\mathbf{b}$}

UV-visible absorption spectra (200-700 nm) were obtained using a Shimadzu UV/2501PC spectrophotometer. Fluorescence spectra were collected using a FluoroMax-4 spectrofluorometer. The relative fluorescence quantum yields were determined by using $10^{-6} \mathrm{M}$ solution of Rhodamine $6 \mathrm{G}$ in ethanol as standard $\left(\Phi_{\mathrm{F}}=\right.$ 0.95). ${ }^{3}$ Organic solvents used in the spectroscopic studies were of spectroscopic grade. Solutions of benzothiazolium derivatives $3 \mathbf{a}-\mathbf{b}\left(\mathrm{ca} .1 .0 \times 10^{-5} \mathrm{M}\right)$ and of the ions under study (ca. $1.0 \times 10^{-2}$ and $1.0 \times 10^{-3} \mathrm{M}$ ) were prepared in UV-grade acetonitrile or acetonitrile/water (90:10). Titrations of the compounds 3a-b in the presence of relevant organic and inorganic anions $\left(\mathrm{AcO}^{-}, \mathrm{F}^{-}, \mathrm{Cl}^{-}, \mathrm{Br}^{-}, \mathrm{CN}^{-}, \mathrm{NO}_{3}^{-}, \mathrm{BzO}^{-}, \mathrm{H}_{2} \mathrm{PO}_{4}^{-}, \mathrm{HSO}_{4}^{-}\right)$, and of alkaline, alkaline-earth and transition metal cations $\left(\mathrm{Cu}^{2+}, \mathrm{Cd}^{2+}, \mathrm{Pd}^{2+}, \mathrm{Ni}^{2+}, \mathrm{Hg}^{2+}\right.$, $\mathrm{Zn}^{2+}, \mathrm{Fe}^{2+}, \mathrm{Fe}^{3+}$ and $\mathrm{Cr}^{3+}$ ) was performed by the sequential addition of the ion stock solution to the benzothiazolium salts solution, in a $10 \mathrm{~mm}$ path length quartz cuvette and absorption emission spectra were measured by excitation at the wavelength of maximum absorption for each compound, with a $2 \mathrm{~nm}$ slit.

\section{Results and discussion}

\subsection{Synthesis and characterization}

Benzothiazolium salts 3a-b were synthesized in low to moderate yields (15-46\%), by a Knoevenagel reaction between benzothiazolium salt $\mathbf{1}$ and aldehydes $\mathbf{2 a - b}$ (Scheme). The new compounds were completely characterized by the usual spectroscopic techniques (Table 1).

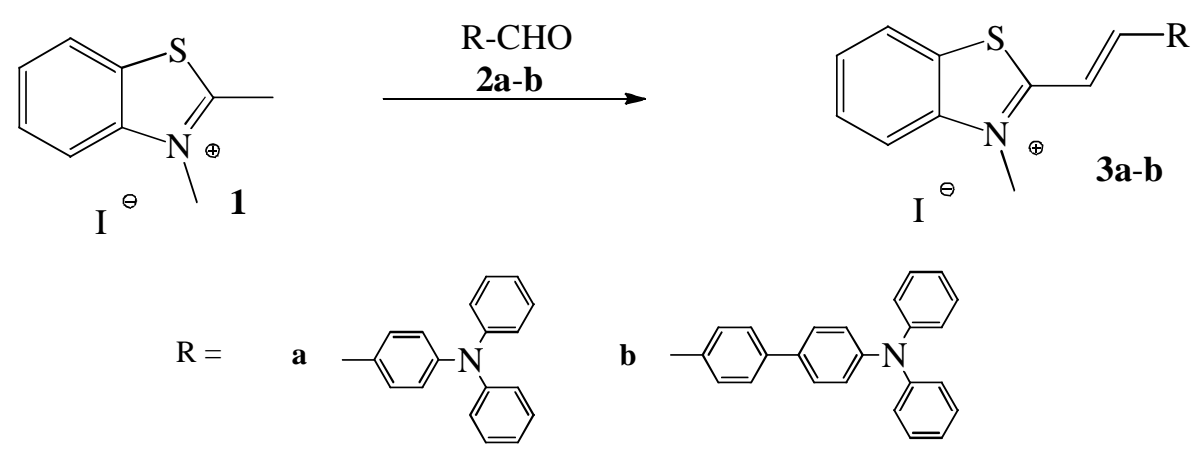

Scheme. Synthesis of benzothiazolium salts $\mathbf{3 a - b}$. 
The absorption and emission spectra of benzothiazolium salts 3a-b were measured in acetonitrile solutions and showed intense lowest energy charge-transfer absorption bands in the UV-visible region between 466 - $509 \mathrm{~nm}$ (absorption) and $576 \mathrm{~nm}$ (emission). The position of these band depends on the length of the $\pi$-bridge (Table 1 , Figure 1). Therefore, compound $\mathbf{3 b}$ bearing an additional phenyl ring on the $\pi$-spacer exhibited a bathochromic shift for the maximum wavelength of absorption (49 $\mathrm{nm})$ compared to 3a. Both compounds were very weakly fluorescent, with wavelengths of maximum emission close to $570 \mathrm{~nm}$ and with relative fluorescence quantum yields in the order of 0.005 .

Table 1. Yields and UV-visible absorption for benzothiazolium salts $\mathbf{3 a - b}$ in acetonitrile solution.

\begin{tabular}{cccc}
\hline \hline & \multirow{2}{*}{$\eta(\%)$} & \multicolumn{2}{c}{ Absorption } \\
\cline { 3 - 4 } & & $\lambda_{\max }(\mathbf{n m})$ & $\log \boldsymbol{\varepsilon}$ \\
\hline \hline 3a & 46 & 509 & 4.31 \\
$\mathbf{3 b}$ & 12 & 466 & 4.11 \\
\hline \hline
\end{tabular}

\subsection{Spectrophotometric titrations of benzothiazolium salts 3a-b with anions and metallic ions}

Evaluation of new benzothiazolium salts $3 \mathbf{a}-\mathbf{b}\left(10^{-5} \mathrm{M}\right)$ as colorimetric chemosensors were carried out in $\mathrm{ACN}$ and $\mathrm{ACN} / \mathrm{H}_{2} \mathrm{O}$ solutions, in the presence of several ions $\left(\mathrm{AcO}^{-}\right.$, $\mathrm{F}^{-}, \mathrm{Cl}^{-}, \mathrm{Br}^{-}, \mathrm{CN}^{-}, \mathrm{NO}_{3}^{-}, \mathrm{BzO}^{-}, \mathrm{H}_{2} \mathrm{PO}_{4}^{-}, \mathrm{HSO}_{4}^{-}, \mathrm{Cu}^{2+}, \mathrm{Cd}^{2+}, \mathrm{Pd}^{2+}, \mathrm{Ni}^{2+}, \mathrm{Hg}^{2+}, \mathrm{Zn}^{2+}, \mathrm{Fe}^{2+}$, $\mathrm{Fe}^{3+}$ and $\mathrm{Cr}^{3+}$ ) with biological, environmental and analytical relevance.

Preliminary tests were carried out by addition of up to 50 equiv of each ion to the solutions of benzothiazolium salts 3a-b in $\mathrm{ACN}$ and in and aqueous mixture $\mathrm{ACN} / \mathrm{H}_{2} \mathrm{O}$ (90:10), revealing a higher selectivity of both compounds in aqueous mixtures (Table 2). It was found that the two benzothiazolium salts displayed a marked colour change upon interaction with $\mathrm{F}^{-}, \mathrm{CN}^{-}$, and $\mathrm{H}_{2} \mathrm{PO}_{4}{ }^{-}$(only for $\mathbf{3 a}$ ) and $\mathrm{Cu}^{2+}$. 
Table 2. Results obtained in preliminary sensing tests for benzothiazolium salts $\mathbf{3}$ in $\mathrm{ACN}$ and $\mathrm{ACN} / \mathrm{H}_{2} \mathrm{O}(90: 10)$ in the presence of several ions.

\begin{tabular}{|c|c|c|c|c|c|}
\hline \multirow{3}{*}{} & \multicolumn{4}{|c|}{$\mathrm{ACN}$} & $\mathrm{ACN} / \mathrm{H}_{2} \mathrm{O}(90 / 10)$ \\
\cline { 2 - 6 } & $\mathrm{CN}^{-}$ & $\mathrm{H}_{2} \mathrm{PO}_{4}^{-}$ & $\mathrm{F}^{-}$ & $\mathrm{Cu}^{2+}$ & $\mathrm{CN}^{-}$ \\
\cline { 2 - 6 } $3 \mathbf{3}$ & $\checkmark$ & $\checkmark$ & $\checkmark$ & $\checkmark$ & $\checkmark$ \\
$3 \mathbf{3 b}$ & $\checkmark$ & & $\checkmark$ & $\checkmark$ & $\checkmark$ \\
\hline
\end{tabular}

For compound 3a, the initial solution in ACN was pink and changed to colourless with cyanide, fluoride and dihydrogenphospate ions, and to a ligher pink with copper ion. For compound $\mathbf{3 b}$, the initial solution in $\mathrm{ACN}$ was coral red and changed to colourless with cyanide and fluoride ions, and to a ligh green with copper ion. A similar preliminary test was carried out in $\mathrm{ACN} / \mathrm{H}_{2} \mathrm{O}$ (90:10) and the initil colour was ligther pink for 3a and ligther coral red for $\mathbf{3 b}$. In this case, higher selectivity was achieved as both compounds only changed colour in the presence of cyanide.

Considering these preliminary results, spectrophotometric titration of compounds $\mathbf{3 a - b}$ in $\mathrm{ACN}$ with these selected ions were undertaken. Titration with $\mathrm{CN}^{-}$revealed a trend in the UV-Vis spectra: the intensity of the longest wavelength absorption band (3a: 508 $\mathrm{nm}$; 3b: $466 \mathrm{~nm}$ ) decreased progressively upon addition of the anion, with the simultaneous growth of a new blue-shifted absorption band located at $300 \mathrm{~nm}$.
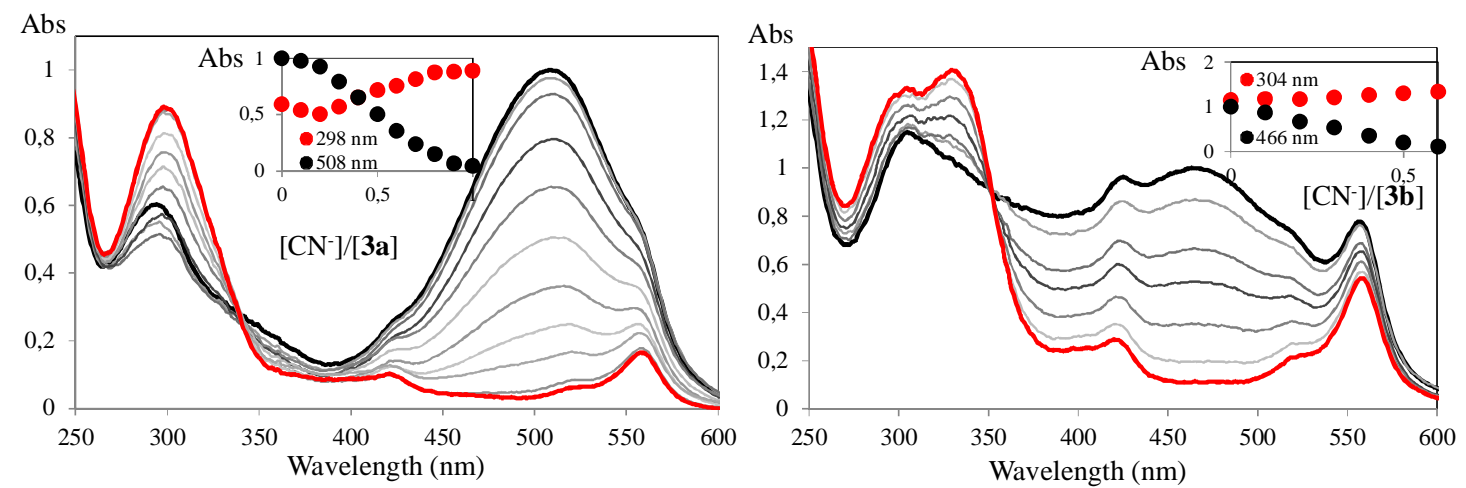

Figure 2: Spectrophotometric titrations of benzothiazolium salts $\mathbf{3 a}$ (left) and $\mathbf{3 b}$ (right) with addition of increasing amounts of $\mathrm{CN}^{-}$in $\mathrm{ACN}$. The inset represents the normalized emission $\left([\mathbf{3 a}-\mathbf{b}]=1 \times 10^{-5} \mathrm{M}, \mathrm{T}=298 \mathrm{~K}\right)$. 
Compound 3a, in the titration with copper, fluoride and $\mathrm{H}_{2} \mathrm{PO}_{4}{ }^{-}$, revealed the same trend observed in the titration with cyanide ion. In the titration with $\mathrm{F}^{-} 22$ equiv were used, 278 equiv were needed for titration with copper and 399 equiv for the titration with $\mathrm{H}_{2} \mathrm{PO}_{4}{ }^{-}$. It can be said that compound $3 \mathbf{a}$ in acetonitrile is more sensitive to the presence of cyanide ion, since to observe the same effect only 1 equiv of the cyanide ion was used.

For compound $\mathbf{3 b}$, in the titrations with copper and fluoride the same effect was observed. There was a decrease in the intensity of absorption at $466 \mathrm{~nm}$, followed by a blue-shift, increasing the intensity of absorption at $304 \mathrm{~nm}$.

Designing selective chemosensors in aqueous medium is a very appealing topic, because there is a high demand for colorimetric/fluorimetric sensors that can be applied in the detection of environmental and biomedical analytes. Therefore, spectrophotometric titrations of compounds 3a-b in $\mathrm{ACN} / \mathrm{H}_{2} \mathrm{O}(90: 10)$ confirmed the preliminary sensing results for both compounds which were selective for the cyanide ion. In figure 3 for compound $\mathbf{3 a}$, as representative example, it can be seen that there was a gradual decrease in absorption intensity upon addition of the cyanide ion, accompanied by a blue-shift with the formation of two new bands at $294 \mathrm{~nm}$ and 348 $\mathrm{nm}$.

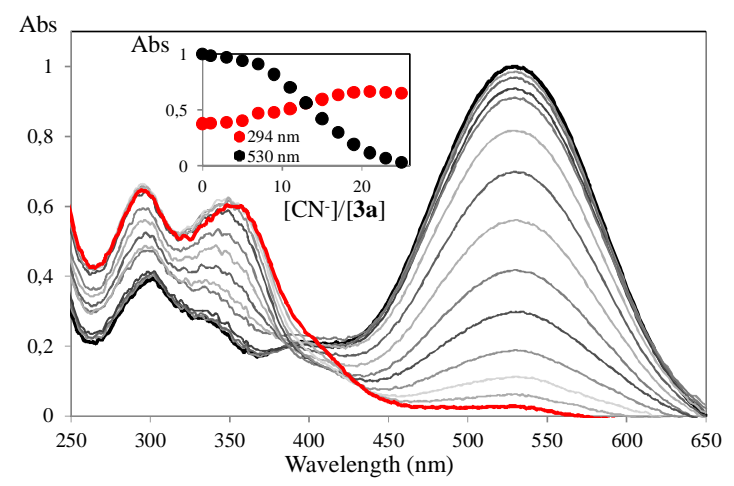

Figure 3: Spectrophotometric titration of compound 3a with addition of increasing amounts of $\mathrm{CN}^{-}$in $\mathrm{ACN} / \mathrm{H}_{2} \mathrm{O}(90: 10)$. The inset represents the normalized emission $\left([\mathbf{3 a}]=1 \times 10^{-5} \mathrm{M}, \mathrm{T}=298 \mathrm{~K}\right)$. 


\section{Conclusions}

The synthesis of new benzothiazolium salts 3a-b was achieved in low to moderate yields by a simple experimental procedure. The sensory ability was evaluated for several ions by spectrophotometric titrations in acetonitrile and acetonitrile/water and it was found that benzothiazolium salts $\mathbf{3 a}$ and $\mathbf{3 b}$ were selective for the cyanide ion in $\mathrm{ACN} / \mathrm{H}_{2} \mathrm{O}(90: 10)$, which is a very promising result as a colorimetric chemosensor for application in aqueous media.

\section{Acknowledgements}

Thank are due to Fundação para a Ciência e Tecnologia (Portugal) and FEDERCOMPETE for financial support through Centro de Química (PEst-C/QUI/UI0686/2013 (FCOMP-01-0124-FEDER-037302)), and a $\mathrm{PhD}$ grant to R.C.M. Ferreira (SFRH/BD/86408/2012). The NMR spectrometer Bruker Avance III 400 is part of the National NMR Network and was purchased with funds from FCT and FEDER.

\section{References}

1. a) Zajac M.; Hrobarik P.; Magdolen P.; Zahradník P. Tetrahedron 2008, 64, 1060510618. b) Brown A. S.; Bernal L.-M.; Micotto T. L.; Smith, E. L.; Wilson J. N. Org. Biomol. Chem. 2011, 9, 2142-2148. c) Xu, J.-F.; Chen, H.-H.; Chen, Y.-Z.; Li, Z.-J.; Wu, L.-Z.; Tung, C.-H.; Yang, Q.-Z. Sens. Actuators B, 2012, 168, 14-19. d) Chao, J.; Li, Z.; Zhang, Y.; Huo, F.; Yin, C.; Liu, Y.; Li, Y.; Wang, J. J. Mater. Chem. B, 2016, 4, 3703-3712. e) Bures, F.; Cvejn, D.; Melánová, K.; Benes, L.; Svoboda, J.; Zima, V.; Pytela, O.; Mikysek, T.; Ruzickova, Z.; Kityk, I. V., Wojciechowski, A.; AlZayed, N. J. Mater. Chem. C, 2016, 4, 468-478. f) Coelho, P. J.; Castro, M. C. R.; Raposo, M. M. M. Dyes Pigments, 2015, 117, 163-169.

2. a) Batista, R. M. F.; Costa, S. P. G.; Raposo, M. M. M. J. Photochem. Photobiol. A, 2013, 259, 33-40. b) Batista, R. M. F.; Costa, S. P. G.; Raposo, M. M. M. Sens. Actuators B, 2014, 191, 791-799. c) Batista, R. M. F.; Costa, S. P. G.; Raposo, M. M. M. Dyes Pigments, 2014, 102, 293-300. d) Marín-Hernández C.; Santos-Figueiroa, L. E.; Moragues, M. E.; Raposo, M. M. M.; Batista, R. M. F.; Costa, S. P. G.; Pardo, T.; Martínez-Mánez, R.; Sancénon, F. J. Org. Chem., 2014, 79, 10752-10761.

3. Kubin, R. F.; Fletcher, A. N. J. Lumin., 1982, 27, 455-462. 